\title{
Material Science \& Engineering International Journal on the way from a toddler to youth
}

\section{Editorial}

Material Science \& Engineering International Journal has undergone the first critical two years, and is steadily walking on the way from a toddler to youth. The journal has published three volumes with 14 issues, 71 articles in total, covering the fundamental of material science, a variety of materials, material characterization, material processing, etc. And the authors are from all over the world.

Phase diagram is the fundamental of material science. Kang presented the 3D stereo display of complex ternary phase diagrams, which greatly helps the understanding of phase diagrams. The improvement of physical and mechanical properties of materials is a main topic in published issues. Huseynova ${ }^{2,3}$ reviewed the solutionprocessed electrical doping of organic semiconductors to improve their electrical properties and dopants for the doping of organic semiconductors by cationic species. Kaliyannan et al., ${ }^{4}$ gave a full view of the effect of carbon based nanofillers on the properties of elastomers. Iwamoto et al., ${ }^{5}$ investigated one kind of nonferrous magnetic alloys manganese-antimony $(\mathrm{MnSb})$ alloy and found the $\mathrm{Mn}_{1.09} \mathrm{Sb}$ phase was tunable exclusively through its composition, which is a promising property for specific applications, and $\mathrm{Mn}_{2} \mathrm{Sb}$ phase formed at high temperatures. García et al., ${ }^{6}$ analyzed the polaron conductivity due to the presence of transition metal oxides in tellurite glasses and found the existence of a not small perturbation given by mobile cations had a strong effect on the non-periodic potential added to the formation of ion-polaron neutral entity in the modified tellurite glassy matrices. Dorozinska et al., ${ }^{7}$ increased the velocity of adhesive polymerization by the introduction of organosilicon acrylates with high dispersion as impurities in ultraviolet adhesives used in the manufacture of precision optical devices. Prátula et al. ${ }^{8}$ synthesized $\mathrm{NiFe}_{2} \mathrm{O}_{4}$ spinel - phosphate (Bi-Ba-Li) glass composite by solid-state reaction. New crystalline magnetic phases developed inside the glassy matrix through controlled heat treatment make the glass composite own excellent magnetic response. Biomaterials and their reaction with body tissue is a research interest as well. Cör ${ }^{9}$ investigated the histological characteristics of periprosthetic tissue around metal on metal hip prostheses (MoM THR) and found extensive lymphocytic infiltration in the periprosthetic tissue around MoM THR is the predominant pattern. However, perivascular lymphoid aggregates are not exclusive characteristics.

Traditional material processing is always the research concern. Bunte \& Deferrari ${ }^{10}$ studied the hot-workability of aeronautical quality titanium alloys through hot torsion testing and verified that at least a $50 \%$ area reduction must be applied to Ti-6Al-4V alloys in order to obtain a fully equiaxial grains after annealing. Additive manufacturing is a very promising manufacturing method and arouses the interests of researchers. Kang et al. ${ }^{11,12}$ investigated the fabrication parameters on the soundness, microstructure and mechanical properties of CuSn 10 alloy and Inconel 718 by selective laser melting method. Heat treatment of the additively manufactured specimens is always necessary for the further improvement of their mechanical properties. Kang et al., ${ }^{13}$ studied the effect of heat treatment on the microstructure evolution of titanium alloy TC4.

\author{
Volume 3 Issue 4 - 2019 \\ Jinwu Kang \\ Tsinghua University, China
}

\begin{abstract}
Correspondence: Kang J, School of Materials Science and Engineering, Key Laboratory for Advanced Materials Processing Technology, Ministry of Education, China,
\end{abstract} Email kangjw@tsinghua.edu.cn

Received: July 19, 2018 | Published: July 22, 2019

Material science and engineering are undergoing ever deepest and widest progress. New materials such as nanomaterials, functional ceramics, organic materials, carbon and biomaterials come to the frontier of research stage instead of traditional metal and alloys represented by iron and steels. Meanwhile, the material characterization becomes more powerful with the appearance of new analysis methods and devices and equipments. Additive manufacturing sprouts like the bamboo shoots just after rain. It expands into a great variety of methods such as selective laser melting (SLM), laser metal deposition (LMD), electron beam melting (EBM), stereos lithography (SLA), selective laser sintering (SLS), and binder jet 3D printing (3DP), fused deposition modeling (FDM), etc. These provide journals including MSEIJ a great opportunity to publish the cutting edge research progress and facilitate the spreading of research achievements. But the situation for journals is not the same. There is always long waiting list of submitted papers for peer review for famed journals in materials science and engineering area. On the other hand, some new journals are still thirsty for paper submission, which threatens the continuity of publishing. There is chance, but chance just stays there away from us. We have to figure out ways to catch the chance. Let more researchers know this journal by advertisement, keep the best paper quality control, dispose manuscripts with quick response by editors and peer reviewers and build reputation step by step. Each year new open access journal about material science and engineering is born, which brings new challenge together with the always existing one by the subscription journals. Although the title of this journal is wide enough to contain everything related to materials, some specific areas and features should be emphasized to symbolize its uniqueness. For example, focus on some kind of new materials or characterization or material processing or modeling and simulation. Quantity of articles is very important for the normal running of this journal, but, quality is the most important issue which finally determines its success. Years later, I am sure that MSEIJ will secure its position in materials science and engineering area.

\section{Funding details}

None.

\section{Acknowledgments}

None. 


\section{Conflicts of interest}

Author declares that there are no conflicts of interest.

\section{References}

1. Kang J. 3D Stereo spatial phase diagram for a typical complex ternary system. Material Sci \& Eng. 2019;3(1):38-40.

2. Huseynov G. Cationic species as dopants for organic semiconductors. Material Sci \& Eng. 2019;3(2):51-53.

3. Huseynova G. Solution-processed electrical doping of organic semiconductors and their application for organic devices. Material Sci \& Eng. 2019;3(3):103-105.

4. Kaliyannan GV, Rathanasamy R, Palaniappan SK. A review on the effect of carbon based nanofillers on the properties of elastomers. Material Sci \& Eng. 2019;3(3):89-101.

5. Iwamoto GY, Iwamoto LAS, Vieira RA. Study of MnSb alloy on the range of $43 \%$ to $50 \%$ of at. $\% \mathrm{Sb}$, revealed an unexpected presence of $\mathrm{MN}_{2} \mathrm{SB}$ phase. Material Sci \& Eng. 2019;3(3):78-80.

6. García LAH, Molina MC, Zoratti M, et al. Ion-polaron interaction in modified tellurite glasses. Material Sci \& Eng. 2019;3(4):113-116.
7. Dorozinska H, Dorozinsky G, Maslov V, et al. The use surface plasmon resonance to determine the optical parameters of UV-adhesive and control polymerization process. Material Sci \& Eng. 2019;3(2):55-58.

8. Prátula PE, Pistonesi CA, Anton MA, et al. Electrical and magnetic response of a phosphate glass - $\mathrm{NiFe}_{2} \mathrm{O}_{4}$ composite. A novel magnetic sensor design. Material Sci \& Eng. 2019;3(1):13-19.

9. Cör A. Histological characteristics of periprosthetic tissue around metal on metal hip prostheses. Material Sci \& Eng. 2019;3(1):33-36.

10. Bunte C, Deferrari N. Study of hot-workability of titanium alloys through hot-torsion testing and its application to the optimization of forging and extrusion processes. Material Sci \& Eng. 2019;3(2):60-61.

11. Kang J, Wang X, Deng C, et al. Effect of hatch distance on CuSn10 specimens by selective laser melting. Material Sci \& Eng. 2019;3(2):63-65.

12. Kang JW, Yi JH, Wang TJ, et al. Effect of laser power and scanning speed on the microstructure and mechanical properties of SLM fabricated Inconel 718 specimens. Material Sci \& Eng. 2019;3(3):72-76

13. Kang J, Dou Z, Deng C, et al. Effect of heat treatment on the microstructure and hardness of the SLMed TC4 alloy specimens. Material Sci \& Eng. 2019;3(3):82-87. 